\title{
Analysis of Statistics Curriculum at Higher Secondary Level in the Province of Sindh
}

\author{
Muhammad Shahid, Dr.Syed Abdul Aziz, Dr.Ahmed Saeed \\ Research Scholar, HIESS, Hamdard University, Karachi,Pakistan \\ Dean of HIESS, Hamdard University, Karachi, Pakistan \\ Research Supervisor, HIESS, Hamdard University, Karachi, Pakistan
}

\begin{abstract}
The study was designed to analyze statistics curriculum at higher secondary level in the province of Sindh. The scope of the study was limited to subject of statistics curriculum. The population of the study was all male and female college teachers of Sindh. The sample size consisted of 60 statistics teachers. Stratified random sampling was used. Questionnaire was used for collection of data. The data analyzed by using descriptive and inferential statistical procedures. Four hypotheses were formulated for the study. The hypotheses were related to the control, sex, age, experience, academic and professional qualification. All of them are held. All the teachers contented with the effectiveness of the present curricula. In item wise analysis teachers were shown concern about training programs, examination system and quality of the textbook. It was recommended that training programs were conducted and quality of textbook were improved.
\end{abstract}

Key Words: Analysis, Curriculum, Statistics, Higher Secondary Level

\section{Introduction}

To meet the challenges in the new era, there was definite need to revise our statistics curriculum. Without effective curriculum the students could not get advantage, and their concepts remained unclear. Statistics is a branch of science. The statistics course which was taught in the entire province of Sindh was not fulfilling the needs of teachers and learners. Teachers and learners were facing problems in explaining and understanding the topic. It showed the weaknesses of the content. Therefore, they required well planed and organized program of statistics. The rationale behind the research on this problem was to analyses the curriculum of statistics at intermediate level in order to find out the deficiencies of curriculum. To elaborate the background, the researcher interviewed some statistics teachers and intermediate students. They were asked about the current curriculum of statistics, most of them replied that the on hand curriculum of statistics has not been modified since long. The students were of the opinion that the content of the course was not updated and do not fulfill the present need. No comprehensive research study had been taken on this subject in the province of Sindh. It was hoped that the research study would meet the required needs.

The overall purpose of the study was to analyze statistics curriculum at higher secondary level in the province of Sindh as viewed by male and female statistics teachers posted in different government colleges of Sindh. For addressing this purpose study tested the hypothesis there will be no significant difference in the opinion of male and female teachers about the effectiveness of existing statistics curriculum at higher secondary level.

The study would help to enhance the statistics curriculum at higher secondary level. The finding of the study will develop the understanding and concepts among all teachers and students of statistics at government colleges of Sindh.

The study was limited to all male and female statistics teachers at government colleges of Sindh. The study was based on the assumptions that Most of the teachers are untrained. Proper teaching skills are not being functioned effectively in Karachi.

\section{Literature Review}

The word education is taken from the Latin word 'educare' which means 'to bring up'. There is also another Latin word 'educare' which means to bring forth. Education, therefore, means both to bring forth as well as bring up. (Dictionary, 1993)[1]

Allah has endows man with curiosity. With this attribute he is always in work to know the nature of the universe and processes going on around him in nature. As this knowledge grows he invents things and employs them for his comfort and convenience. In this regards statistics plays a vital role, by the theory of statistics or more briefly statistics we mean the science which deals with the exposition of statistical methods. It is in fact a body of principles that has been developed to serve as a guide for sound statistics and sound statistical methods which underlines and justifies the formulae used in the application of statistical methods to various fields of inquiry. 
According to Encyclopedia of American's Science may be defined as "systematized positive knowledge or what has been taken as positive knowledge at different ages and in different places", "Science is a systematized body of knowledge", "Science is nothing but organized common sense", "Science is a heap of truth" (Yadav, 1992).[2]

Saylor and Alexander (1956) defined curriculum as the "sum total of school efforts to influence the learning, whether in the classroom on the play ground or out of school.[3]

Hilda Taba (1962) gave the most comprehensive definition of the curriculum, "a curriculum usually contains a statement of aims and specific objectives. It indicates some selection and organization of content. It either implies or manifests certain pattern of learning or teaching".[4]

Malik (1983) elaborate on science education in Pakistan as; "The Science courses taught were content loaded with a weak component of laboratory practical. Those engaged in the teaching of science were very simple. Chalk and talk, rather talk was only method employed. Rote Learning was the common and most praised way of learning. Syllabuses of science were outdated both in terms of the subject matter and in terms of the way of presentation."'[5]

Iqbal (1990) viewed science education in Pakistan as, "At the time of independence in 1947, Pakistan did not inherit a strong background in science and technology, science teaching at primary level was almost absent. Middle intermediate levels classes had a weak component of science in the curriculum. Higher secondary has since subject iii the form of physics and Physics. The teaching and learning of science at Higher Secondary Intermediate levels level takes place mostly through textbooks. These textbooks are not of good quality as for as their role for teaching aid is concerned. Too many facts are given mostly in general form without much account of application. Science teaching is dominated by lecture method".[6]

Hashmi (1996) indicated that now the modern literacy definition is to make know how about scientific equipment which is daily used, and it is called as scientific and technological literacy (STL) Pakistan did not make science curriculum according to this definition till now. He also elaborates that, science is not only the presentation of concepts Science should not be thought by lecture method .Observation and project method should be adopted for science teaching Law cost material should be used for making science projects and scientific examples should given from the daily life. Rote-memorization should be discouraged. The teachinglearning should be-student centered and logical.[7]

\section{Evaluation}

The evaluation is the integral and essential part of the curriculum planning. It continues activity and not a tail end process. Evaluation is the process of determining what the actual educational outcomes are, and of comparing them with the expected outcomes. It also involves judgments about the nature and desirability of any demonstrated changes. Judgment of this kind obviously bears directly on educational objectives. Evolution is the systematic process of collecting and analyzing data in order to determine whether and to what degree, objectives have been achieved. Evaluation is the systematic process of collection and analyzing data in order to make decisions. The finding of the study was that curriculum development was not done on the basis of initial survey and not based on tryout and experiment. (Gay, 1985)[8]

\section{Methodology}

The overall strategy of the study was survey. The population of the study comprised of all male and female statistics teachers at government colleges of Sindh. Total sample size was 60 (34 male and 26 female teachers). A tailor-made questionnaire comprising of 18 items was used as a research instrument. The population of the study was all male and female college teachers of Sindh. Stratified random sampling was used. The hypothesis was tested using t-test.

\section{Null Hypothesis}

There will be no significant difference in the view of male and female college teachers regarding the effectiveness of existing Statistics curriculum at higher secondary level.

\section{Analysis of Problem}

1. $H_{0}: \mu_{1}=\mu_{2}$

2. $H_{1}: \mu_{1} \neq \mu_{2}$

3. $\alpha=0.05$

4. Test Statistic :

$$
\mathrm{t}=\frac{\overline{X_{1}}-\overline{X_{2}}}{S E_{\overline{X_{1}}}-\overline{X_{2}}}
$$

5. Decision rule : Reject $H_{0}$ if computed $\mathrm{t} \geq 1.96$

6. Degree of freedom $(\mathrm{df})=\mathrm{df}=\left(N_{1}-1\right)+\left(N_{2}-1\right)=(26-1)+(34-1)=25+33=58$ 
Table 1: Application of t-test for testing the significance of hypothesis

\begin{tabular}{|l|l|l|l|l|l|l|}
\hline Respondents & $\mathrm{n}$ & Mean & S.D & S.E & t-value & Result \\
\hline Male teachers & 36 & 66.0 & 7.733 & 2.01 & 0.84 & $H_{0}$ Accepted \\
\hline Female teachers & 26 & 64.3 & 7.735 & & & \\
\hline
\end{tabular}

Referring to the table " $t$ " it was found that tabulated value of " $t$ " $=1.96$ with $\mathrm{df}=58$ at $\alpha=0.05$ is greater than the computed value of $\mathrm{t}=0.84$. Therefore, the null hypothesis is accepted and it is concluded that there is no significant difference between in the views of female and male college teachers organizing effectiveness of statistics curriculum at colleges of Sindh.

\section{Conclusion}

Majority of statistics teachers were not trained according to the changing world of knowledge, so InService training must be arranged. Most of the teachers were agree to develop the activity based curriculum of statistics because the students would take more interest. The examination system is not assessing properly. Students focus on getting marks rather than learning, so examination system must focus on learning rather than trend of getting marks. Teachers know the problems of students and need of society therefore, maximum participation of the teachers is ensured in the curriculum development process.

Most of teachers agree that mostly students face difficult to understand the concepts. Therefore, practical application must be focused.

Most of teachers agreed that number of solved examples should be increased, which create the interest in students. Organization of the topic should be simple to complex. Language should be easy and understandable. The content helped in understanding the basic concepts of statistics, although their effectiveness for developing critical thinking was uncertain. Diagram and graphs should be clear and precise.

\section{Recommendations}

- The academically expert and, professionally competent science teachers (statistics) may be appointed in the educational institutions.

- Experienced teachers may be involved in the curriculum development process of science (statistics) education.

- In-service training may be arranged according to the future needs.

- Loaded curriculum may be avoided; curriculum may be selected according to the available academic time period.

- Counseling and guidance in the science (statistics) may be provided.

- Internal evaluation system may be introduced.

- Monitoring and evaluation is based upon scientific principles.

\section{References}

[1]. Dictionary of English Language and Culture. (1993). UK. Longman Group Limited.

[2]. Yadav, M.S. (1992). Teaching of Science. Anmol publication New Delhi, India, pp. 1-9.

[3]. Saylor, J.A, and W.M. Alexander. (1954). Curriculum Planning for better Teaching and Learning, Richert and company, New York, pp. 6-7.

[4]. Taba, H. (1962). Curriculum Development: Theory and Practice, Harcourt, Brace and company, New York, p.7.

[5]. Malik. Rasul Saib. (1983). The System of Education in Pakistan. NBF, Islamabad, p.48.

[6]. Iqbl, M.Z. (1990). Science Education in Pakistan - A New Look, In: MM. Zafar (ed), Science Technology and Development Pakistan Council for Science and Technology, Islamabad, pp. 1-10.

[7]. Hashmi, K.A. (1996). Science For All. In: M.A. Khalid, (ed). Taleemi Zawiae.Pakistan Education Foundation, Lahore, pp.39-41.

[8]. Gay, L.R. (1985). Educational Evaluation and Measurement, Longman’s Green Co, New York, pp. 6-9. 